\title{
Correction to: Tumor-suppressing effect of bartogenic acid in ovarian (SKOV-3) xenograft mouse model
}

\author{
Vishal Kumar Dubey ${ }^{1,2} \cdot$ Aditi Budhauliya $^{1} \cdot$ Manu Jaggi ${ }^{1} \cdot$ Anu T. Singh ${ }^{1} \cdot$ Satyendra K. Rajput ${ }^{2,3,4}$
}

Published online: 21 September 2021

๑) Springer-Verlag GmbH Germany, part of Springer Nature 2021

\section{Correction to: Naunyn-Schmiedeberg's Archives of Pharmacology (2021) 394:1815-1826 https://doi.org/10.1007/s00210-021-02088-0}

The original version of this article contains mistake.

Reason: Production inadvertently used an incorrect version of Figure 7.

This is being corrected in this publication.

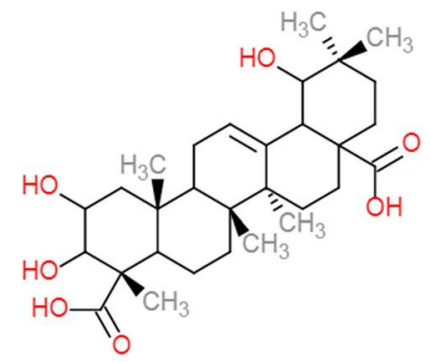

Bartogenic acid<smiles>CC1(C)CCC2(C(=O)O)CC[C@]3(C)C(=CC[C@H]4[C@@]5(C)CCC(O)C(C)(C)C5CC[C@]43C)C2C1</smiles>

Oleanolic acid<smiles>CC1[C@@H](C)CCC2(C(=O)O)CC[C@]3(C)C(=CC[C@@H]4[C@@]5(C)CCC(O)C(C)(C)[C@@H]5CC[C@]43C)[C@H]12</smiles>

Ursolic acid
The original article can be found online at https://doi.org/10.1007/ s00210-021-02088-0.

\section{Vishal Kumar Dubey}

vishal.dubey@daburresearch.in; vdubey64@gmail.com

1 Dabur Research Foundation, 22, Site IV, Sahibabad, Ghaziabad 201010, Uttar Pradesh, India

2 Amity Institute of Pharmacy, Amity University Uttar Pradesh, Sector-125, Noida 201313, Uttar Pradesh, India

3 Amity Institute of Indian System of Medicine (AIISM), Amity University Uttar Pradesh, Sector-125, Noida 201313, Uttar Pradesh, India

4 Department of Pharmaceutical Sciences, Gurukula Kangri Vishwavidyalaya, Jagjeetpur, Haridwar 249404, Uttarakhand, India
Publisher's note Springer Nature remains neutral with regard to jurisdictional claims in published maps and institutional affiliations. 